\title{
Т.Л. Лабутина
}

Институт всеобщей истории Российской академии наук, 119334 г. Москва, Российская Федерация

\section{Великий князь Павел Петрович в восприятии английских послов}

В статье речь идет о восприятии английскими послами сына императрицы Екатерины II - великого князя Павла Петровича. В исторической литературе данная проблема прежде не являлась предметом специального исследования. Автор подчеркивает, что будущий наследник российского престола представлял для правящих кругов Великобритании далеко не праздный интерес, и потому послы самым внимательным образом наблюдали за его поведением, а также окружением, в особенности за теми людьми, которые могли оказывать на него влияние. Особое внимание дипломаты уделяли характеру, образованию, личной жизни великого князя, его взаимоотношениям с императрицей. Хотя оценки послов не всегда отличались объективностью, они во многом дополняют и расширяют представления наших современников об императоре Павле । в бытность его великим князем.

Ключевые слова: Россия, Великобритания, XVIII век, Екатерина II, Павел I, английские послы при русском дворе

ССЫЛКА НА СТАТЬЮ: Лабутина Т.Л. Великий князь Павел Петрович в восприятии английских послов // Локус: люди, общество, культуры, смыслы. 2020. Т. 11. № 2. C. 11-22. DOI: 10.31862/2500-2988-2020-11-2-11-22 


\section{T.L. Labutina}

Institute of World History, Russian Academy of Sciences, Moscow, 119334, Russian Federation

\section{Grand Duke Pavel Petrovich in perception of the British ambassadors}

The article deals with the perception by the British ambassadors of the son of Empress Catherine II - Grand Duke Pavel Petrovich. In historical literature, this issue has not previously been the subject of special research. The author emphasizes that the future heir to the Russian throne was far from idle interest for the ruling circles of Great Britain, and therefore the ambassadors carefully watched his behavior, as well as the people around him, especially those who could influence him. Diplomats paid special attention to the character, education, personal life of the Grand Duke, and his relationship with the Empress. Although the opinions of the ambassadors were not always objective, they greatly complement and expand the views of our contemporaries about Emperor Paul I when he was Grand Duke.

Key words: Russia, Great Britain, XVIII century, British ambassadors at the Russian Court, Catherine II, Paul I

CITATION: Labutina T.L. Grand Duke Pavel Petrovich in perception of the British ambassadors. Locus: People, Society, Cultures, Meanings. 2020. Vol. 11. No. 2. Pp. 11-22. (In Russ.) DOI: 10.31862/2500-2988-2020-11-2-11-22

В последние годы одним из востребованных направлений в отечественной исторической науке сделалась имагология (от лат. Imago образ), которая изучает восприятие народами друг друга, а также механизмы формирования внешнеполитических стереотипов. В русле данного направления нами были проделаны исследования, результаты которых опубликованы в ряде научных изданий [5; 6]. Данная статья является своеобразным продолжением начатых изысканий.

Обращаясь к дипломатической переписке британских послов при дворе Екатерины II [7], мы обратили внимание на то, что все дипломаты в донесениях, помимо служебной информации, сообщали в Лондон 
о многом, что они видели в России. Впечатления о Екатерине II, ее внутренней и внешней политике, министрах и придворных, обычаях и нравах русских людей, а также неординарных событиях в жизни страны - все это нашло отражение в их депешах, отправляемых на родину. Безусловно, прежде всего послы останавливались на характеристиках самой императрицы, а также ее ближайшего окружения. Не был обойден вниманием дипломатов и сын Екатерины - великий князь Павел Петрович. Будущий наследник российского престола представлял для правящих кругов Великобритании далеко не праздный интерес, и потому послы самым внимательным образом наблюдали за поведением великого князя, а также его окружением, в особенности за теми людьми, которые могли оказывать на него влияние. Заметим, что в исторической литературе данная проблема прежде не являлась предметом специального исследования. Нас, в первую очередь, интересовало, какие черты характера великого князя выделяли дипломаты, как они воспринимали отношения императрицы с сыном, видели ли в Павле Петровиче будущего российского императора, наконец, насколько объективными были их оценки?

Одним из первых английских послов, оставившим свои заметки о великом князе, оказался граф Бэкингэмшир. В то время, когда он прибыл в Россию, в 1762 г., цесаревич был еще ребенком и не играл заметной роли при дворе Екатерины II. Возможно, поэтому Бэкингэмшир в своих мемуарах написал о нем немного, упомянув, что великий князь «хорош фигурой и элегантно танцует», «живо все воспринимает» и отличается хорошей памятью. Дипломат также отметил, что Павел Петрович, хотя и не выказывает особого прилежания, тем не менее, «имеет лучшие познания, чем обычно имеют принцы в его возрасте» [3, с. 123]. Поскольку его учителя «способны и усердны», а императрица «не дает ему особой поблажки» [Там же], он сможет достичь значительных успехов, заключал Бэкингэмшир.

Посол Чарльз Кэткарт о великом князе сообщал: Павел Петрович «подает большие надежды, а здоровье его скорее нежное, чем слабое, и, по всей вероятности, укрепится с годами при большей свободе и движении» [4, с. 14]. Дипломат заметил, что императрица старается ему угождать и «публично» обращает на сына гораздо большее, чем прежде, внимание. Приближенные Екатерины оказывают великому князю особую честь. В их числе граф Григорий Орлов, который относится к нему «с особенной внимательностью» [Там же, с. 34].

Большое внимание характеристике великого князя уделил дипломат Роберт Ганнинг. Первое знакомство с ним позволило послу составить представление о его характере и наклонностях. «Полагают, что 
великому князю небезызвестно то положение, в котором он находится, - докладывал Ганнинг в Лондон в депеше от 28 июля 1772 г. - Беспечность и необдуманность... не составляют его недостатков, но критические обстоятельства, его окружающие, до того развили в нем природную скрытность... что он, по-видимому, ничем не интересуется и не обращает внимания ни на что, кроме пустых забав» [4, с. 300]. Ганнинг полагал, что воспитанием великого князя «постыдно или вернее преднамеренно пренебрегали», объясняя это «ленивым и пристрастным к наслаждениям направлением Панина, который за исключением честности и бескорыстия не обладает ни одним качеством, желательным для его воспитанника» [Там же].

Об образовании великого князя подробно извещал официальный Лондон известный дипломат Джеймс Гаррис. С самого детства, писал он, Павел Петрович был поручен заботам графа Никиты Панина, а также дворянину из Лифляндии господину Остервальду, ныне занимающему должность сенатора. На взгляд Гарриса, оба наставника не составили «правильной системы образования» подопечного и не получили на этот счет никаких указаний от императрицы, которая «оказалась менее внимательной и заботливой относительно успехов воспитания своего сына» [8, с. 1502] по сравнению с заботой об образовании подданных. В результате, великий князь ознакомился лишь с немногими предметами. Так, от Остервальда он получил «весьма основательные понятия» о внутреннем управлении империи, а от графа Панина «порядочное знание» [Там же] новейшей истории Европы. Учителя читали ему лекции по искусству, а также знакомили с философскими учениями. Однако великий князь, на взгляд Гарриса, «мало воспользовался этими стараниями» [Там же]. Поскольку Павел, по его мнению, от природы «был неловок и угловат в манерах» [8, с. 1503], то большую часть времени он предпочитал уделять танцам, верховой езде и французскому языку. И именно в этих предметах он достиг «значительной степени совершенства» [Там же].

В какой мере информация Гарриса об образовании цесаревича Павла Петровича была объективной? Согласно исследованиям историков, первым воспитателем Павла был дипломат Федор Бехтеев. В 1760 г. по указанию императрицы Елизаветы Петровны главным наставником юноши был назначен Никита Иванович Панин, обладавший обширными познаниями и разделявший идеи Просвещения. Именно он обозначил весьма обширный круг тем и предметов, которые должен был изучать его воспитанник. Панин выбрал также учителей-предметников. Так, Закон Божий преподавал митрополит Платон; Дж. Миллико обучал музыке, а Гранже - танцам. Однако этим образование великого 
князя не ограничивалось. Ему преподавали историю, географию, арифметику, астрономию, иностранные языки (французский, немецкий, латинский, итальянский), русский язык, рисование, фехтование. Не без влияния графа Панина Павел ознакомился с трудами французских просветителей: Вольтера, Дидро, Монтескье. По мнению историков, к учебе у Павла были неплохие способности, у него было развито воображение, он любил проводить время за чтением. В целом, образование Павла Петровича, на взгляд исследователей [11; 12], было лучшим, какое только можно было получить в то время.

Отмечая недостатки в образовании Павла Петровича, Гаррис в то же время признавал достоинства воспитания, привитые ему наставниками. Благодаря внимательному отношению к его нравственности, их наставления «исправили много природных недостатков», и великий князь «сделался гораздо лучшим человеком» [4, с. 300], чем если бы оказался предоставлен самому себе. Павел отличался умеренностью в пище и питье и, благодаря этой воздержанности, считал англичанин, он укрепил свой от природы слабый организм.

После того, как великий князь достиг совершеннолетия, отношение к нему со стороны императрицы заметно изменилось, что не осталось незамеченным дипломатами. «В последнее время он (Павел) встречает со стороны императрицы внимание, с которым она не привыкла относиться к нему, - свидетельствовал Роберт Ганнинг, - что доказывает, что ее опасения усиливаются» [Там же]. Павел надеялся, продолжал дипломат, что ему наконец-то будет предоставлена «некоторая независимость и составлен двор» [Там же], однако этого не произошло, и его воспитатель Никита Панин продолжал сохранять ту же власть, какая ему до этого принадлежала. Екатерина всерьез опасалась, что ее сын станет предъявлять права на власть. В России не существует «разделения власти», а потому, пояснял Ганнинг, когда великий князь получит власть, он должен получить ее «всецело» [4, с. 376]. И если императрица «будет действовать осторожно, но в то же время энергично, то время это весьма удалено, в противном случае она находится в критическом положении» [Там же].

Совершеннолетие великого князя разбудило надежды недоброжелателей императрицы, считавших, что он должен занять трон на законных основаниях. И вскоре Павел почувствовал к себе расположение этих людей. Послы иностранных государств внимательно наблюдали за развитием событий. Французский просветитель Д. Дидро, находившийся в это время при дворе Екатерины II, рассыпаясь в комплиментах императрице, не забывал и о великом князе. «Лесть его (Дидро. - Т.Л.) относительно великого князя была также сильна, - свидетельствовал 
Ганнинг, - но к чести этого молодого принца он оказал ей не менее презрения, чем отвращения к его пресловутым и зловредным принципам философии» [4, с. 340]. Между тем, французы продолжали плести интриги. Ганнинг в секретном послании в Лондон от 5 января 1773 г. сообщал: французские эмиссары «намекали нескольким лицам» [Там же], что интересы России требуют вступления на престол великого князя. Императрица полагает, будто новые министры Франции и Испании едут в Россию «с надеждой на возможность революции» [Там же]. Однако Ганнинг был иного мнения. Он считал, что Екатерина II нашла способ повлиять на сына, дав согласие на его брак. Дипломат предлагал своему руководству занять более активную позицию по отношению к великому князю как к наследнику престола: «Не следует ли заранее оказать внимание этому молодому принцу, который склонен к лести и может быть расположен в нашу пользу, по крайней мере, в настоящую минуту, знаками отличия и внимания и бездельными подарками, как например английские экипажи, лошади и т.д.?» [Там же].

Ганнинг обращал внимание на то, что некоторые друзья великого князя советовали ему «не щеголять» популярностью, которую он приобрел, и он подчинился этому совету весьма неохотно. Посол поведал об одном инциденте, который произошел в ноябре 1773 г. Павлу Петровичу подали на ужин блюдо сосисок, «кушанье, до которого он большой охотник» [4, с. 389], в котором он обнаружил стеклянные осколки. Великий князь вскочил из-за стола и, взяв с собой блюдо, отправился в покои императрицы, где «с величайшим раздражением высказал ей, что этот случай доказывает ему намерение его отравить» [Там же]. Императрица, продолжал посол, «была чрезвычайно поражена этим подозрением, так же, как и небрежностью прислуги, послужившей единственным поводом к тому» [Там же]. Между тем, она выразила «сильное беспокойство» не самим происшествием, а реакцией на него сына, посчитав его высказывания «ребяческими и неосторожными» [Там же]. Тем не менее, после случившегося Екатерина приняла решение отправиться с великим князем в Царское Село, где у нее будет больше времени и возможностей «изучить образ мыслей сына» [4, с. 390].

В начале 1774 г. отношения императрицы и великого князя заметно улучшились. На взгляд Ганнинга, Павел Петрович это доказал прежде всего своим обращением с господином Дидро, хотя «многоречивые комплименты» последнего, равно, как и его «отвратительные мнения», внушали ему «столько же презрения, как и ужаса» [Там же, с. 397]. В то же время императрица предприняла меры, чтобы ограничить возможные контакты великого князя с народом. В секретном послании от 16 марта 1775 г. Ганнинг извещал госсекретаря: «Популярность, заявленная 
великим князем в день, когда он ездил по городу во главе своего полка, разговаривал с простым народом и позволял ему тесниться вокруг себя так, что толпа совершенно отделяла его от полка, и явное удовольствие, которое подобное обращение доставило народу, как полагают, весьма не понравилось (императрице. - T.Л.), и потому будут приняты меры к тому, чтобы великий князь не имел более подобного случая показаться народу» [4, с. 451].

Особое внимание послы уделяли семейной жизни великого князя. Павел Петрович был женат дважды. В первый раз он женился в 1773 г. на великой княжне Наталье Алексеевне, урожденной принцессе Вильгельмине Гессен-Дармштадтской. Императрица однажды заявила, что обязана великой княгине за то, что «ей возвращен ее сын» [Там же, с. 409] и что она докажет ей свою признательность за такую услугу. И, действительно, свидетельствовал Ганнинг, Екатерина «никогда не пропускает случая приласкать... принцессу, которая, обладая даже меньшим умом, чем великий князь, несмотря на то, приобрела над ним сильное влияние» [Там же]. Ганнинг пришел к выводу: общество жены «составляет единственное отдохновение великого князя», и желание приобрести популярность, «замечаемое в великом князе в продолжение некоторого времени», теперь «совершенно исчезло» [Там же]. Дипломат подчеркивал: великий князь «не имеет никакого характера», легко подвержен влиянию других лиц, и этим пользуется императрица, которая выбирает из его окружения людей, способных в значительной степени внушить ему те мысли, которые она сочтет нужным [4, с. 410].

Посол Джеймс Гаррис также отмечал, что до своего брака Павел Петрович находился «в самом полном повиновении» у императрицы и был окружен только теми лицами, которых она ему назначила, и «если он имел некоторую сыновнюю привязанность, то происходила она больше из страха, чем из сердечного чувства» [8, с. 1503]. После женитьбы оказывать влияние на великого князя стала его супруга, сумевшая, на взгляд Гарриса, «отыскать искусство управлять им» [Там же]. И вскоре Павел удалил из своего окружения тех немногих друзей, которых до этого выбирал сам, и с тех пор, продолжал дипломат, «его общество, его развлечения, даже самые чувства, все вполне подчинилось его жене» [Там же]. Однако подобное подчинение супруге, на взгляд англичанина, не принесло радости великому князю: «нрав его из живого и быстрого сделался грустным, тяжелым и апатичным» [Там же].

Примечательно, что в одной из своих депеш Гаррис обратил внимание на отношения великой княгини с графом Андреем Разумовским, который был у нее «близким человеком» [Там же]. Дипломат полагал, что граф получал указания «вместе с большей частью своего дохода» 
от французских министров [8, с. 1503]. Естественно, подобное поведение невестки не могло не вызвать осуждения императрицы, однако, замечал Гаррис, «слова ее оставались совершенно безуспешными: молодая принцесса была властолюбива и решительна» [Там же]. Неизвестно, к чему могло привести соперничество между этими дамами, рассуждал посол, если бы ни внезапная кончина великой княгини. Она скончалась при родах вместе с младенцем 15 апреля 1776 г. Британская исследовательница И. де Мадариага подчеркивала, что по слухам, ходившим при дворе, ребенок был от любовника княгини, А.К. Разумовского. Возможно, предполагала историк, догадываясь о любовной связи невестки, императрица и не выказала особой печали по поводу ее кончины [2, с. 550]. Что касается Павла Петровича, то он горевал недолго. Уже спустя три месяца состоялась его помолвка с принцессой Софией Доротеей Вюртембергской, дочерью Фридриха II (в православии - Марией Федоровной). Встречу великого князя с будущей женой устроил в Берлине сам Фридрих Великий. Павел был пленен статной блондинкой с приятным лицом.

О новой супруге великого князя Гаррис отзывался довольно лестно. Ее характер, полагал он, «совершенно противоположен нраву прежней... Она кротка, приветлива и глубоко проникнута понятием о супружеских обязанностях» [8, с. 1504]. Под ее влиянием великий князь сделался разговорчивым, веселым и «чаще проявляет личную волю» [Там же]. Великая княгиня «постоянной услужливостью» и вниманием заслужила привязанность Павла, который «очень ее любит» [Там же]. «В настоящую минуту они совершенно счастливы друг другом, но я опасаюсь, - приходил к заключению Гаррис, - что счастье их не может быть продолжительно посреди двора, столь безнравственного и так странно составленного» [Там же]. Великая княгиня должна обладать необыкновенной «долей твердости и добродетели» [Там же], полагал дипломат, чтобы обойти многочисленные искушения, которые встретятся ей на пути.

Надо отметить, что Джеймс Гаррис внимательно наблюдал за жизнью наследника российского престола. В депеше госсекретарю от 3 октября 1778 г. он писал: «Вот уже несколько времени, как я обещал сообщить вам все сведения, которые мне удастся получить относительно способностей и характера наследника империи» [8, с. 1502]. Касаясь политических предпочтений Павла Петровича, дипломат подметил их непостоянство, утверждая, что «его политика теперь клонится на сторону Пруссии столько же, как прежде он оказывал сочувствия Франции» [Там же, с. 1504]. Причину тому Гаррис усматривал во влиянии Панина, который инициировал поездку Павла в Берлин. Не менее ощутимым 
в принятии решения о путешествии в Пруссию оказалось также «особое расположение» [8, с. 1504] великой княгини к своему семейству в этой стране.

Гаррис приходил к заключению о том, что Павел Петрович, «не будучи одарен высшими способностями... обладает достаточной долей понятливости, чтобы управлять страной» [Там же]. А для этого ему остается только «справиться с некоторым непостоянством в привязанностях и нерешительностью в действиях» [8, с. 1505], что посол относил к молодости великого князя, а также к зависимому его от императрицы положению [Там же].

Впрочем, спустя полгода Гаррис изменил свое мнение о способностях великого князя управлять Российской империей. Павел Петрович, «вследствие природной застенчивости и непостоянства нрава, которое не сглаживается с летами, - приходил к заключению Гаррис, - окажется неспособным управлять этой огромной и буйной империей» [9, с. 153-154]. По-видимому, того же мнения придерживалась и императрица, когда решила сделать своим престолонаследником старшего внука Александра, о чем посол докладывал в Лондон в декабре 1782 г. [10, с. 876].

Отношения Екатерины II с сыном оставались сложными. В ряде своих депеш Гаррис обращал внимание на полную подчиненность, даже в мелочах, великокняжеского двора императрице. Без ее разрешения никто не имеет доступа к великокняжеской чете, писал дипломат в депеше 1 октября 1778 г. Фавориты Екатерины относились к молодым супругам с высокомерием и равнодушием. «С великим князем и великой княгиней Потемкин и его партия обращаются, как с лицами, не имеющими никакого значения, - докладывал Гаррис в Лондон 29 января 1779 г. - Великий князь чувствует это пренебрежение» [9, с. 146]. Посол обращал внимание на «обидное равнодушие» [Там же] Екатерины к сыну и невестке.

Подтверждением тому могли послужить описанные Гаррисом 22 ноября 1782 г. события, связанные с возвращением великокняжеской четы из Европы. Они путешествовали инкогнито под именами графа и графини Северных (дю Нор), посетили Италию, где удостоились аудиенции папы римского, и Францию. Их путешествие продолжалось 428 дней. Между тем, прием, который они встретили после длительного отсутствия, оказался более чем прохладным. «Свидание между императрицей и их императорскими высочествами произошло совершенно частным образом, без посторонних свидетелей, - сообщал Гаррис. Продолжалось оно не более нескольких минут и, вероятно, ни с той, ни с другой стороны не было выражено большой радости или нежности» $[10$, с. 872]. Вечером состоялся прием, на котором им представили иностранных министров. Затем великокняжеская чета навестила 
графа Панина и 20 минут провела с императрицей. «Из всего, что я мог узнать, - писал Гаррис, - я заключил, что они также недовольны приемом, им оказанным, как императрица сожалеет об их возвращении, и взаимное неудовольствие, преобладающее с обеих сторон, вероятно, произведет неприятные сцены» [10, с. 873].

Ухудшению отношений Екатерины с великокняжеской четой могло способствовать также то обстоятельство, полагал Гаррис, что во время путешествия они «сделали огромный долг» [Там же], который невозможно скрыть от императрицы. И это еще больше усилило то раздражение и ту «неестественную вражду», которые «существуют между ними» [10, с. 873-874]. Не исключено, что немалую часть долга составили расходы на наряды великой княгини. Возвращаясь из Европы, писал Гаррис, Мария Федоровна привезла с собой не менее 200 сундуков, «наполненных газом, лентами и другой подобной дрянью» [Там же, с. 867]. Заметим, что сведения, приведенные послом, вызвали сомнения у автора комментариев к его корреспонденции, утверждавшего, что «государыня Мария Федоровна, напротив, и сама не любила тратиться на наряды, и не допускала к тому окружающих ее лиц» [Там же, с. 868].

Как бы то ни было, но после возвращения из заграничного путешествия поведение великого князя и великой княгини претерпело изменения. «Они ведут почти уединенный образ жизни, - свидетельствовал Гаррис, - исключили из своего общества всех своих прежних любимцев и, по-видимому, хотят впредь руководиться в своих поступках одной только волей императрицы» [Там же, с. 876]. Задаваясь вопросом, чем объяснялась подобная перемена в поведении великокняжеской четы, дипломат высказывал предположение, что, во-первых, они нашли графа Панина «слишком ослабевшим», чтобы он мог поддержать их или дать совет; а, во-вторых, они убедились, что почти все лица, которые их сопровождали во время путешествия, «их выдали» [Там же]. Однако решающим стало известие о намерении императрицы устранить великого князя от наследства, передав престол своему старшему внуку. Впрочем, продолжал Гаррис, какими бы причинами не были вызваны перемены, поведение великокняжеской четы сделалось «благоразумным и основательным» [Там же]. Однако это не изменило отношения к супругам со стороны императрицы. Она «так сильно предубеждена против них, что их поведение нисколько не встречает с ее стороны того одобрения, которого бы заслуживало. Теперь она называет их сдержанными, молчаливыми и рассерженными, говорит, что их испортили заграничные связи и... они уже не могут вернуться к обычаям своей страны. Словом, - заключал Гаррис, - она заранее решила, что будет ими недовольна, а потому угодить ей уже невозможно» [10, с. 877]. 
Справедливости ради стоит отметить, что при всем сложном характере отношений Екатерины с сыном она не скупилась в расходах на его содержание и те прихоти, к которым великий князь был привязан. Как отмечал польский ученый К. Валишевский, Павел получал 175 тыс. руб. в год для себя и 75 тыс. руб. для своей жены, не считая денег, отпускаемых на его двор. Исследователь заключал, что с материальной стороны Павел «был обставлен очень прилично» [1, с. 23]. Тем не менее, великий князь постоянно нуждался в деньгах и, чтобы раздобыть их, прибегал даже к «таким постыдным средствам, как соглашение с поставщиками императрицы» [Там же]. Ученый объяснял это тем, что управляющий нагло обворовывал Павла, бедные родственники Марии Фёдоровны его обирали, и сам он разорялся на бесполезные постройки и тратил безумные деньги на свою дорогую и смешную игрушку - гатчинскую армию.

Итак, как мы могли убедиться, английские послы внимательно наблюдали за жизнью и деятельностью будущего наследника престола. Они изучали его характер, останавливались на взаимоотношениях с императрицей, давали оценки его поступкам. Особое внимание послы уделяли образованию, семейной жизни Павла Петровича, а также его окружению. И хотя их характеристики не всегда отличались объективностью, они позволяют существенно дополнить и расширить представления наших современников об императоре Павле I в бытность его великим князем.

\section{Библиографический список / References}

1. Валишевский К. Павел I. М., 2003. [Waliszewski K. Pavel I [Le Fils de la grande Catherine, Paul I]. Moscow, 2003.]

2. де Мадариага И. Россия в эпоху Екатерины Великой. М., 2002. [de Madariaga I.M. Rossiya v epohu Ekateriny Velikoy [Russia in the age of Catherine the Great]. Moscow, 2002.]

3. Дипломатическая переписка английских послов и посланников при русском дворе // Сборник Императорского Русского исторического общества. T. XII: Дипломатическая переписка английских послов и посланников при русском дворе, с 1762 по 1769 г. включительно. Сообщено из английского государственного архива и архива Министерства Иностранных Дел. Ч. 1. СПб., 1873. [Diplomatic correspondence of English ambassadors and envoys at the Russian court. Sbornik Imperatorskogo Russkogo istoricheskogo obshchestva. Vol. XII: Diplomatic correspondence of English ambassadors and envoys at the Russian court, from 1762 to 1769 inclusive. Reported from the English State Archive and the archive of the Ministry of Foreign Affairs. Part 1. St. Petersburg, 1873.]

4. Дипломатическая переписка английских послов и посланников при русском дворе // Сборник Императорского Русского исторического общества. T. XIX: Дипломатическая переписка английских послов и посланников 
при русском дворе, с 1770 по 1776 г. включительно. Сообщено из английского государственного архива и архива Министерства Иностранных Дел. Ч. 2. СПб., 1876. [Diplomatic correspondence of English ambassadors and envoys at the Russian court. Sbornik Imperatorskogo Russkogo istoricheskogo obshchestva. Vol. XIX: Diplomatic correspondence of English ambassadors and envoys at the Russian court, from 1762 to 1769 inclusive. Reported from the English State Archive and the Archive of the Ministry of Foreign Affairs. Part 2. St. Petersburg, 1882.]

5. Лабутина Т.Л. Англичане в допетровской России. СПб., 2011. [Labutina T.L. Anglichane v dopetrovskoy Rossii [The English in Russia since Peter the Great]. St. Petersburg, 2011.]

6. Лабутина T.Л. Британцы в России в XVIII веке. СПб., 2013. [Labutina T.L. Britantsy $\mathrm{v}$ Rossii $\mathrm{v}$ XVIII veke [The British in Russia in the 18th century]. St. Petersburg, 2013.]

7. Лабутина Т.Л. Британские дипломаты и Екатерина II. Диалог и противостояние. СПб., 2019. [Labutina T.L. Britanskie diplomaty i Ekaterina II. Dialog i protivostoyanie [British diplomats and Catherine II. Dialogue and confrontation]. St. Petersburg, 2019.]

8. Лорд Мальмсбюри в России в царствование Екатерины II // Русский архив. 1874. T. I. № 6. C. 1465-1512. [Lord Malmesbury in Russia during the reign of Catherine II. Russkiy arhiv. 1874. Vol. I. No. 6. Pp. 1465-1512. (In Russ.)]

9. Лорд Мальмсбюри в России в царствование Екатерины II // Русский архив. 1874. T. I. № 7. C. 143-186. [Lord Malmesbury in Russia during the reign of Catherine II. Russkiy arhiv. 1874. Vol. I. No. 7. Pp. 143-186. (In Russ.)]

10. Лорд Мальмсбюри (Гаррис) в России в царствование Екатерины II // Русский архив. 1874. Т. II. № 11. С. 737-897. [Lord Malmesbury (Harris) in Russia during the reign of Catherine II. Russkiy arhiv. 1874. Vol. II. No. 11. Pp. 737-897. (In Russ.)]

11. Песков А.М. Павел I. М., 2000. [Peskov A.M. Pavel I [Paul I]. Moscow, 2000.]

12. Порошин С.А. Сто три дня из детской жизни императора Павла Петровича (Неизданная тетрадь «Записок С.А. Порошина»). 1765 г. // Русский архив. 1869. Вып. 1. № 8. С. 349-440. [Poroshin S.A. One hundred and three days from the childhood of Emperor Paul I (Unreleased copybook "Notes of S.A. Poroshin"). 1765. Russkiy arhiv. Vol. I. No. 8. Pp. 349-440. (In Russ.)]

Статья поступила в редакцию 20.02.2020, принята к публикации 08.05.2020

The article was received on 20.02.2020, accepted for publication 08.05.2020

\section{Сведения об авторе / About the author}

Лабутина Татьяна Леонидовна - доктор исторических наук, профессор; старший научный сотрудник Центра истории межкультурных коммуникаций стран Запада и Востока, Институт всеобщей истории Российской академии наук, г. Москва

Tatyana L. Labutina - Dr. Hab. in History, main researcher at the Center "History of cross-culture communications of the West and East", Institute of World History, Russian Academy of Sciences, Moscow

E-mail: tlabutina2007@yandex.ru 